\title{
Parents and Mating Systems Affect the Transfer of Gynoecious Flowering to Chinese Monoecious Cucumbers
}

\author{
Qi Zhang ${ }^{1}$, August C. Gabert ${ }^{2}$, and James R. Baggett ${ }^{3}$ \\ Department of Horticulture, Oregon State University, Corvallis, OR 97331-2911 \\ Additional index words. Cucumis sativus, vegetable breeding, $\mathrm{F}_{1}$ hybrids
}

\begin{abstract}
Monoecious cucumber (Cucumis sativus L.) parents with high, medium, and low percentage of nodes with distillate flowers had a stronger effect on the percentage of gynoecious plants in $F_{1}$ and $F_{2}$ progenies than did degree of gynoecious expression in incompletely gynoecious parents. Highest percentages of gynoecious plants were obtained by using both gynoecious and monoecious parents with the highest level of distillate flowering tendency. According to our data, monoecious parents with a low percentage of distillate flowering nodes should be avoided when gynoeciousness is transferred to monoecious cultivars. Self-pollination of gynoecious $F_{2}$ plants, requiring induction of staminate flowers by chemical treatment, was more effective in obtaining a high percentage of gynoecious plants in $\mathbf{F}_{3}$ progenies than selfing predominately gynoecious plants, or sibmating predominately gynoecious plants.
\end{abstract}

Monoecious plants of cucumber vary quantitatively in sex expression from predominately staminate to predominately distillate. Some monoecious lines produce staminate and distillate flowers throughout the growing season. Others produce staminate flowers at the base, followed by a mixture of staminate and distillate flowers, and then only distillate flowers (Kubicki, 1965, 1969a, 1969b, 1972; Shifriss, 1961).

Gynoecious plants bear only distillate flowers that are mostly solitary in the leaf axils of the main axis arid side branches. The gynoecious character is not always complete or stable in cucumbers. In this report, "PG" will refer to plants or lines that produce predominately distillate flowers, while the term "gynoecious" will refer to completely distillate plants. Gynoecious cucumbers can be induced to produce staminate flowers, when necessary, by treatment with silver ions, such as from $\mathrm{Ag}\left(\mathrm{SO}_{2} \mathrm{O}_{3}\right)_{2}$ (Den Nijs et al., 1980; Lower et al., 1978).

A challenge to breeders is development of stable gynoecious lines for use as parents in $\mathrm{F}_{1}$ hybrids. The development of lines with various levels of distillate flowering stability may be accomplished by repeated selection and self-pollination of monoecious plants that are predominately pistillate. Selected gynoecious plants may be intercrossed or crossed with monoecious or other sex types and reselected to develop new parental lines. In any of these approaches, obtaining stable gynoecy is difficult because gynoecious sex expression of cucumber is conditioned by a gene $F$, subject to considerable influence from modifying genes and environmental factors (Cantliffe, 1981; Ito and Saito, 1957; Lower et al., 1975). The $F$ gene interacts with alleles at the $a$ and $m$ loci, and the interaction produces, unless modified by genetic background or environment, monoecious $\left(\mathrm{m}^{+} \mathrm{m}^{+} \mathrm{F}+\mathrm{F}_{--}\right)$, androecious $\left(--F^{+} F^{+} a a\right)$, hermaphroditic $(\mathrm{mm}$ $F F--)$, and gynoecious $\left(\mathrm{m}^{+} \mathrm{m}^{+} \mathrm{FF}--\right)$ genotypes (Galun, 1961; Kubicki, 1969a, 1969c; Rosa, 1928; Shifriss, 1961; Tkachenko, 1935; Wall, 1967). The gene $F$ may also be modified by an intensifier gene $I n-F$, which increases femaleness (Kubicki,

\footnotetext{
Received for publication 18 Mar. 1991. Accepted for publication 2 Jan. 1992. Submitted as Oregon Agricultural Experiment Station Technical Paper no. 9552. The cost of publishing this paper was defrayed in part by the payment of page charges. Under postal regulations, this paper therefore must be hereby marked advertisement solely to indicate this fact.

'Graduate Research Assistant.

${ }^{2}$ Courtesy Professor, Plant Breeder, SunSeeds Co., Brooks, OR 97305. 'Professor.
}

1969b). Choice of gynoecious parents is an important consideration when developing or improving gynoecious lines. Therefore, a study was designed to determine the influence of the level of distillate flowering tendency in PG and monoecious lines and of mating systems on the efficiency of converting Chinese monoecious cucumber cultivars to the gynoecious condition.

\section{Materials and Methods}

The PG parents used in this study were segregating inbred lines having $43 \%, 67 \%$, and $91 \%$ gynoecious plants in preliminary tests and arbitrarily designated LF, MF, and $\mathrm{HF}$, respectively. In the experiments, gynoecious plants bore only distillate flowers on the first 15 nodes. Three Chinese cultivars were used as the monoecious parents. Their percentage of distillate flowering nodes among the first 15 nodes was 36, 46, and 54, respectively. They were designated as $\mathrm{LN}, \mathrm{MN}$, and $\mathrm{HN}$ (Table 1). Fruit length and fruit ridging were used as markers to help determine success in combining gynoeciousness with the typical Chinese slicer fruit traits.

All crosses were made in greenhouses. Field studies were eondueted in 1987 on the research farm of SunSeeds Co., Brooks, Ore., using commercial cucumber production practices typical of the region, which included sprinkler irrigation when needed to maintain normal growth.

Effect of parental distillate flowering level. In this experiment, PG lines G19 (HF), G16 (MF), and G15 (LF) were crossed with monoecious parents M18 (HN), M3 (MN), and M2 (LN) to make nine $F_{1}$ combinations. The $F_{1}$ populations were arranged in a randomized complete-block design with two replications. Each plot contained 100 plants of one cross spaced 20 $\mathrm{cm}$ apart in rows $150 \mathrm{~cm}$ apart. The respective $\mathrm{F}_{2}$ progenies were planted in an adjacent area with the same arrangement; except that a completely randomized design was used. From the time the flower buds could be identified through development of the 15th node plants were examined weekly and the sex of each flower bud on the first 15 nodes was recorded. Each plant was discarded after the first 15 nodes were observed. The per-

\footnotetext{
Abbreviations: HF, high female; HN, high distillate flowering percentage; LF, low female; LN, low distillate flowering percentage; MF, medium female; MN, medium distillate flowering percentage.
} 
Table 1. Designation, flowering type, and source of cucumber lines used as parents.

\begin{tabular}{llccc}
\hline \hline \multicolumn{5}{c}{ Percentage } \\
Code name & Type $^{z}$ P F N $^{y}$ or & G Y $^{\mathrm{x}}$ ) & Class $^{w}$ & Source” \\
\hline $\begin{array}{lllll}\text { Chinese type } \\
\text { M2-- }\end{array}$ & M & 36 & LN & NSCC, China \\
M3-- & M & 46 & MN & NSCC, China \\
M18 & M & 54 & HN & NSCC, China \\
American type & & & & \\
G15-- & PG & 43 & LF & SunSeeds \\
G16-- & PG & 67 & MF & SunSeeds \\
European type & & & & \\
G19-- & PG & 91 & HF & SunSeeds \\
\hline
\end{tabular}

${ }^{2} \mathrm{M}=$ monoecious lines, $\mathrm{PG}=$ predominately gynoecious lines.

${ }^{\mathrm{y}} \mathrm{PFN}=$ percentage of pistallate flowering nodes in monoecious parents.

${ }^{x} \mathrm{~Gy}=$ percentage of gynoecious plants in predominately gynoecious (PG) parents.

"LN, MN, and $\mathrm{HN}=$ low, medium, and high percentage of female flowering nodes in monoecious parents. LF, MF, and $\mathrm{HF}=$ low, medium, and high percentage of gynoecious plants.

"NSCC: Northern series of Chinese cucumbers.

centage of gynoecious plants was calculated from the weekly counts.

Effect of mating systems on transfer of gynoecy. The effect of mating systems on the occurrence of gynoeciousness in progeny generations was determined in $\mathrm{F}_{3}$ families from $\mathrm{F}_{2}$ progenies from the crosses G19 $(\mathrm{HF}) \times \mathrm{M} 18(\mathrm{HN}), \mathrm{G} 16(\mathrm{MF}) \times \mathrm{M} 18$ $(\mathrm{HN})$, and G15 (LF) $\times$ M18 (HN). Additionally, in the cross G19 $(\mathrm{HF}) \times \mathrm{M} 18(\mathrm{I}-\mathrm{IN})$, the effect of mating system on recovery of gynoecious plants with Chinese slicer fruit type (long-ridged fruit) was determined. For each cross, we studied $15 \mathrm{~F}_{3}$ families that were derived as follows: 1) five families from selfing PG $F_{2}$ plants, 2) five families from selfing (using chemical induction of staminate flowers) gynoecious $\mathrm{F}_{2}$ plants, and 3) five families produced as half-sibs of gynoecious by sister $\mathrm{PG} \mathrm{F}_{2}$ plants. The $\mathrm{F}_{3}$ families were grown in a. split-plot experiment with crosses. as unreplicated whole plots and mating systems as split-plot treatments with randomized replication of families within mating systems. The five families within each cross $\mathrm{x}$ mating system combination comprised five replications of mating systems.

The percentage of gynoecious plants in each family was determined weekly from the sex of the flowers at the first 15 nodes.

All data were transformed by arcsin square root because they were proportional.

\section{Results and Discussion}

Effect of parental distillate flowering level. The monoecious parent had a significant influence, at $P=0.01$, on the percentage of gynoecious $F_{1}$ plants. However, the effect of degree of femaleness in the PG parent was not significant. There was no interaction between PG and monoecious parents. Means for $\mathrm{HN}, \mathrm{MN}$, and $\mathrm{LN}$ were different for each gynoecious parent (Table 2), and overall (column) means were significantly different. The dominant influence of the monoecious parent was evident, since the percentage of gynoecy was low (near 0\%) in $\mathrm{F}_{1}$ progeny when the $\mathrm{LN}$ parent was used, regardless of the $\mathrm{PG}$ parent used,

The level of distillate flowering of both the monoecious and
Table 2. Effects of levels of female flowering in predominately distillate and monoecious parents on the percentage of gynoecious plants in $\mathrm{F}_{1}$ and $\mathrm{F}_{2}$ progenies.

\begin{tabular}{|c|c|c|c|c|c|c|c|c|}
\hline \multirow{3}{*}{$\begin{array}{l}\text { Pistillate } \\
\text { flowering } \\
\text { parent }\end{array}$} & \multicolumn{8}{|c|}{ Monoecious parent ${ }^{\mathrm{y}}$} \\
\hline & \multicolumn{4}{|c|}{$F_{1}$ progeny $^{x}$} & \multicolumn{4}{|c|}{$\mathrm{F}_{2}$ progeny $^{\mathrm{w}}$} \\
\hline & HN & $\mathrm{MN}$ & $\mathrm{LN}$ & Mean & $\mathrm{HN}$ & $\mathrm{MN}$ & $\mathrm{LN}$ & Mean \\
\hline HF & \multicolumn{8}{|c|}{32.0 a 11.0 b 2.2 c 15.136 .9 ap 32.0 ap 21.0 ap $30.0 \mathrm{P}$} \\
\hline MF & $32.2 \mathrm{a}$ & $6.0 \mathrm{~b}$ & $0.6 \mathrm{c}$ & 13.0 & 35.6 a & 30.2 a & $19.8 \mathrm{~b}$ & $28.5 \mathrm{P}$ \\
\hline LF & $21.4 \mathrm{a}$ & $6.9 \mathrm{~b}$ & $0.9 \mathrm{c}$ & 9.7 & $29.5 \mathrm{a}$ & $17.7 \mathrm{bc}$ & $12.8 \mathrm{~b}$ & 20.0 \\
\hline Mean & $28.5 \mathrm{a}$ & $8.0 \mathrm{~b}$ & $1.3 \mathrm{c}$ & & $34.0 \mathrm{a}$ & $26.6 \mathrm{~b}$ & $17.9 \mathrm{c}$ & \\
\hline
\end{tabular}

${ }^{2} \mathrm{HF}, \mathrm{MF}$, and LF indicate high, medium, and low degrees of female expression in predominately distillate (PG) flowering parents.

'HN, MN, and LN indicate high, medium, and low percentage of distillate flowering nodes in monoecious parents.

${ }^{x}$ Mean separation within rows $(\mathrm{a}, \mathrm{b}, \mathrm{c})$ by $\operatorname{LSD}(P=0.05)$ derived from arcsin-transformed data. The effects of pistiflate flowering (PG) parent (within columns) were nonsignificant.

"Mean separation within rows $(\mathrm{a}, \mathrm{b}, \mathrm{c})$ at $P=0.05$. Mean separation within columns $(\mathrm{P}, \mathrm{Q})$ at $P=0.05$.

gynoecious parents had a significant $(P=0.01)$ influence on the percentage of gynoecious plants in the $\mathrm{F}_{2}$ generation. There was no interaction of PG parent with monoecious parent. The overall mean effects (column means) of the three monoecious parents were significantly different, with the highest percentage of gynoecious plants occurring when the $\mathrm{HN}$ parent was used (Table 2). Not all the differences from the influence of the three PG parents were significant. The overall means for gynoecious parent effects (row means) were the same for HF and MF. The percentage of gynecious plants was significantly reduced when the LF parent was used in the crosses (Table 2).

The results shown in Table 2 indicate the importance of selecting the highest possible level of gynoecious sex expression in both PG and monoecious parents for production of gynecious hybrids, or to provide $\mathrm{F}_{2}$ populations for selection of gynoecious lines. Use of LF parents should be avoided. Each parent appeared to influence the percentage of gynoecious progeny plants independently; so that the highest level of gynoecious flowering tendency was achieved by use of HF and HN parents.

Effect of mating systems on transfer of gynoecy. In all three crosses and in the overall mating system means from the three crosses, families derived from selfed gynoecious $\mathrm{F}_{2}$ selections (System C) were significantly higher in percentage of gynoecious plants than families obtained by selfing $\mathrm{PG} \mathrm{F}_{2}$ plants (System B), or families derived from half-sib-mating gynoecious plants with PG sister selections (System A) (Table 3). Values obtained from Systems A and B did not differ at $P=0.05$. Due to the sensitivity of sex expression in cucumber, some $\mathrm{F}^{2}$ plants may have been selected in error as PG or gynoecious plants because they were modified by environmental factors. This error could have led to higher variability in the percentage of gynoecious plants among tested families.

There was a trend among the crosses for the HF, MF, and LF parents to result in higher, intermediate, and lower percentages of gynoecious plants, respectively (Table 3), but the differences among crosses could not be properly tested statistically because crosses were not replicated. There was no interaction between crosses and mating systems.

Of the three crosses shown in Table 3, only HF $(\mathrm{G} 19) \times \mathrm{HN}$ (M18) resulted in $\mathrm{F}_{2}$ segregation for both levels of gynoecy and presence or absence of the Chinese monoecious cucumber character long-ridged fruit. The effect of mating systems on percentage of gynoecious plants with long-ridged fruit in $\mathrm{F}_{3}$ families 
Table 3. Effect of mating systems on the percentage of $F_{3}$ plants in $\mathrm{F}$ families.

\begin{tabular}{lcccc}
\hline \hline & \multicolumn{3}{c}{ Percentage of gynoecious plants } \\
\cline { 2 - 4 } & \multicolumn{3}{c}{ Mating systems $^{z}$} & \\
\cline { 2 - 4 } Cross $^{y}$ & $\mathrm{~A}$ & $\mathrm{~B}$ & $\mathrm{C}$ & Mean \\
\hline HF (G19) $\times$ HN (M18) & $53.4 \mathrm{a}^{\mathrm{x}}$ & $59.4 \mathrm{a}$ & $93.3 \mathrm{~b}$ & 68.7 \\
& $(40.5 \mathrm{a})^{\mathrm{w}}$ & $(34.0 \mathrm{a})$ & $(72.2 \mathrm{~b})$ & $(48.9)$ \\
MF (G16) $\times$ HN (M18) & $52.9 \mathrm{a}$ & $52.4 \mathrm{a}$ & $77.9 \mathrm{~b}$ & 61.1 \\
LF (G15) $\times$ HN (M18) & $41.6 \mathrm{a}$ & $45.5 \mathrm{a}$ & $64.4 \mathrm{~b}$ & 49.2 \\
Mean & $49.3 \mathrm{a}$ & $51.1 \mathrm{a}$ & $78.6 \mathrm{~b}$ & \\
\hline
\end{tabular}

${ }^{2}$ A, Half-sib-mating: Gynoecious, plants pollinated by predominately distillate (PG) sisters. B, Self: Selected predominately distillate (PG) plants selfed with pollen from their own staminate flowers. C, Induced self: Gynoecious plants selfed with pollen from silver ion-induced staminate flowers.

${ }^{y} \mathrm{HF}, \mathrm{MF}$, and LF = high, medium, and low levels of distillate flowering in $\mathrm{PG}$ lines. $\mathrm{HN}=$ monoecious lines with high percentage of distillate flowering nodes.

${ }^{x}$ Mean separation within rows by LSD $P=0.05$, derived from arcsintransformed data. Means within columns were not tested because crosses were not replicated.

"Percentage of gynoecious plants with long-ridged fruits typical of Chinese monoecious cucumbers. Only cross HF (Gy 19) $\times$ HN (M18) produced segregation for long-ridged fruit.

from this cross (Table 3, in parenthesis) was significant at $P=$ 0.01 . The percentage of gynoecious plants with long-ridged fruit produced by mating systems A (gynoecious plants pollinated by PG sisters) and B (selfed PG plants) was not different. A significantly higher percentage of gynoecious plants with longridged fruit were produced by mating system $\mathrm{C}$ (selfed gynoecious plants). The ratio of percentage of gynoecious plants with long-ridged fruit: total percentage of gynoecious plants for mating systems A, B, and C, respectively, was $0.76,0,57$, and 0.77 . These values suggest that the mating system effect on percentage of gynoecious plants with long-ridged fruit is, mostly, just a reflection of differences in total percentage of gynoecious plants resulting from these "mating systems.

\section{Litkerature Cited}

Cantliffe, D.J. 1981. Alteration of sex expression in cucumber due to changes in temperature, light intensity, and photoperiod. J. Amer. Soc. Hort. Sci. 106(2):133-136.

Dens Nijs, A.P.M. and D.L. Visser. 1980. Induction of male flowering in gynoecious cucumbers (Cucumis sativus L.) by silver ions. Euphytica 29:273-280.

Galun, E. 1961. Study of the inheritance of sex expression in the cucumber. The interaction of major genes with modifying genetic and non-genetic factors. Genetics 32:134-163.

Ito, H. and T. Saito. 1957. Factors responsible for the sex expression of Japanese cucumber. VII. Effects of long day and high night temperature treatment applied for short duration at the various stages of seedling development on the sex expression of flowers. J. Jpn. Soc. Hort. Sci. 26:149-153.

Kubicki, B. 1965. New possibilities of applying different sex types in cucumber breeding. Genetics Polonica 6241-250.

Kubicki, B. 1969a. Investigations on sex determinination in cucumber (Cucumis sativus L.). III. Variability of sex expression in the monoecious and gynoecious lines. Genetics Polonica 10:3-22.

Kubicki, B. 1969b. Investigations on sex determination in cucumber (Cucumis sativus L.) V. Genes controlling intensity of femaleness. Genetics Polonica 10:69-86.

Kubicki, B. 1969c. Investigations on sex determination in cucumbers (Cucumis sativus L.). W. Androecism. Genetics Polonica 10:8799.

Kubicki, B. 1972. The mechanism of sex determination in flowering plants. Genetics Polonica 13:53-66.

Lower, R. L., J.D. McCreight, and O.S. Smith. 1975. Photoperiod and temperature effects on growth and sex-expression of cucumber. HortScience 10:318.

Lower, R. L., D.M. Pharate, and E.K. Horst. 1978. Effects of silver nitrate and gibberellic acid on gynoecious cucumber. Cucurbit $\mathrm{Ge}$ net. Coop. Rpt. 1:8-9.

Rosa, J.T. 1928. The inheritance of flower types in Cucumis and Citrullis. Hilgardia 3:233-250.

Shifriss, O. 1961. Sex control in cucumbers. J. Hered. 52:5-12.

Tkachenko, N.N. 1935. Preliminary results of a genetic investigation of the cucumber, Cucumis sativus L. Bul. Applied Plant Breeding Ser. 2(9):311-356.

Wall, J.R. 1967. Correlated inheritance of sex expression and fruit shape in Cucumis. Euphytica 28:251-255. 